\title{
The relationship between early reversibility test and maximal inspiratory pressure in patients with airway obstruction
}

This article was published in the following Dove Press journal:

International Journal of COPD

5 May 2014

Number of times this article has been viewed

\section{Sevket Ozkaya' \\ Adem Dirican ${ }^{2}$ \\ Sule Ozbay Kaya ${ }^{3}$ \\ Rabia C Karanfil ${ }^{3}$ \\ Merve G Bayrak ${ }^{4}$ \\ Ozgür Bostancl ${ }^{5}$ \\ Ferah Ece'}

'Department of Pulmonary Medicine, Faculty of Medicine, Bahcesehir University, Istanbul, ${ }^{2}$ Department of Pulmonary Medicine, ${ }^{3}$ Department of Physical Therapy and Rehabilitation Clinic, Samsun Medicalpark Hospital, ${ }^{4}$ Department of Pulmonary Medicine, Samsun Chest Diseases and Thoracic Surgery Hospital, ${ }^{5}$ Academy of Sports, Ondokuzmayis University, Samsun, Turkey
Correspondence: Sevket Ozkaya Samsun Medicalpark Hospital, Department of Pulmonary Medicine, Samsun, PO 55200, Turkey

$\mathrm{Tel}+905324741309$

Fax +90362 3II 4050

Email ozkayasevket@yahoo.com
Abstract: Maximal inspiratory pressure (MIP) is a marker for assessing the degree of respiratory muscle dysfunction. Muscle dysfunction represents a pathophysiological feature of chronic obstructive pulmonary disease. We aimed to determinate the MIP value in patients with airway obstruction, to evaluate the change in MIP with bronchodilator drug, and to show the relationship between the changes in MIP and disease characteristics. We evaluated 21 patients with airway obstruction at the Department of Pulmonary Medicine, Samsun Medicalpark Hospital, Samsun, Turkey. We performed pulmonary function tests, measurement of MIP values, and reversibility tests with salbutamol. The baseline spirometry results were: mean forced vital capacity (FVC), 3,017 $\pm 1,020 \mathrm{~mL}$ and $75.8 \% \pm 20.8 \%$; mean forced expiratory volume in 1 second $\left(\mathrm{FEV}_{1}\right), 1,892 \pm 701 \mathrm{~mL}$ and $59.2 \% \pm 18.2 \%$; $\mathrm{FEV}_{1} / \mathrm{FVC}, 62.9 \% \pm 5.5 \%$; peak expiratory flow, $53 \% \pm 19 \%$. The pre-bronchodilator MIP value was $62.1 \pm 36.9 \mathrm{cmH}_{2} \mathrm{O}$. The reversibility test was found to be positive in $61.9 \%$ of patients with salbutamol. The absolute change and percentage of change in $\mathrm{FEV}_{1}$ were $318 \pm 223 \mathrm{~mL}$ and $19.8 \% \pm 16.7 \%$, respectively. The MIP value was increased by $5.5 \mathrm{cmH}_{2} \mathrm{O}(8.8 \%)$ and was $67.7 \pm 30.3 \mathrm{cmH}_{2} \mathrm{O}$ after bronchodilation. There was no significant relationship between age, $\mathrm{FEV}_{1}$, reversibility, and change in MIP with bronchodilator. However, the increase in MIP with bronchodilator drug was higher in patients with low body mass index $\left(<25 \mathrm{~kg} / \mathrm{m}^{2}\right)$. We noted a $13.1 \%$ increase in $\mathrm{FVC}$, a $19.8 \%$ increase in $\mathrm{FEV}_{1}$, a $20.2 \%$ increase in peak expiratory flow, and an $8.8 \%$ increase in MIP with salbutamol. In conclusion; MIP increases with bronchodilator therapy, regardless of changes in lung function, in patients with airway obstruction. The reversibilty test can be used to evaluate change in MIP with salbutamol.

Keywords: asthma, COPD, maximal inspiratory pressure, MIP, reversibility test, salbutamol

\section{Introduction}

Lung hyperinflation is a consequence of airway obstruction, increased airway resistance, and treatment to compliance in patients with chronic obstructive pulmonary disease (COPD), which may result in respiratory muscle weakness. Muscle dysfunction represents a pathophysiological feature of COPD. According to reported articles, Maximal inspiratory pressure (MIP) is a marker for assessing the degree of respiratory muscle dysfunction. The measurement of maximum static mouth pressures, made against an occluded airway - MIP and maximal expiratory pressure (MEP) - is the most widely used, and one simple way to gauge power of respiratory muscles and quantify the severity of disease. MIP and MEP values were lower in patients with severe obstruction, compared with healthy subjects. MIP decreased in patients with mild and moderate functional impairment. ${ }^{1-4}$ 
In patients found to have airway obstruction, evaluation of acute response to bronchodilators - the test of reversibility of airway obstruction - is a commonly-used procedure in clinical and research studies. Salbutamol is a short-acting $\beta 2$-adrenergic receptor agonist (SABA) used for the treatment and assesement of early reversibilty in patients diagnosed as having obstructive lung disease. Usually, forced expiratory volume in 1 second $\left(\mathrm{FEV}_{1}\right)$ or forced vital capacity (FVC) values, before and after administration of the bronchodilator, are compared and the change computed. ${ }^{5}$

We aimed to 1) show the determination of MIP values in patients with airway obstruction, 2) evaluate the change in MIP with bronchodilation, and 3) show the relationship between the changes in MIP and disease characteristics.

\section{Materials and methods}

We evaluated 21 patients at the Department of Pulmonary Medicine, Samsun Medicalpark Hospital, Samsun, Turkey, who met the inclusion criteria specified below:

1. Currently symptomatic (cough, dyspnea, and/or wheezing);

2. Presence of airway obstruction in spirometry $\left(\mathrm{FEV}_{1} / \mathrm{FVC}\right.$ $\leq 70 \%$ of expected value);

3. Had never used bronchodilators before; and

4. Had not received short- or long-acting inhaled bronchodilator therapy within the previous 12 hours.

We performed pulmonary function tests, measurement of MIP values, and reversibility tests with salbutamol.

\section{Pulmonary function test and reversibility assessment}

Pulmonary function tests were performed according to European Respiratory Society standards. ${ }^{6,7}$ Basal FEV $_{1}$ and $\mathrm{FEV}_{1} / \mathrm{FVC}$ values were measured by the same physician using the MIR MiniSpir ${ }^{\circledR}$ PC-Based USB Spirometer (MIR Medical International Research, Waukesha, WI, USA) in an outpatient clinic setting following a 30-minute resting period. The test was performed in the seated position with the nose clamped and nasal respiration hindered. Patients performed the forced expiratory maneuver at least three times, and the maximum $\mathrm{FEV}_{1}$ value was recorded as the basal value.

\section{Measurement of MIP}

A MicroRPM respiratory pressure meter (Micro Medical, Chatham, UK) was used to measure respiratory muscle strength. MIP was measured from residual volume and the MEP was measured from total lung capacity. The patient should maintain inspiratory pressure for at least 1 (or up to 3 ) seconds, and the greatest negative pressure sustained for at least 1 second (not a transient spike) should be recorded. These durations are estimated by the individual supervising the test. The patient should rest for about 1 minute, and the maneuver should be repeated five times. Pre- and post-bronchodilator values were recorded.

\section{Reversibility test}

Following baseline spirometry, subjects inhaled salbutamol (Ventolin $^{\circledR}$; GlaxoSmithKline, London, UK) $(100 \mu \mathrm{g}=4$ inhalations; total dose $=400 \mu \mathrm{g}$ ) administered using a pressurized metered-dose inhaler with a spacer (Ventolin ${ }^{\circledR}$; GlaxoSmithKline). Spirometry was performed 15 minutes later. Reversibility levels were evaluated (according to American Thoracic Society guidelines) ${ }^{6}$ as the absolute change in $\mathrm{FEV}_{1}$ and percentage change from initial $\mathrm{FEV}_{1}$, calculated as: post-FEV ${ }_{1}-$ pre- $-F_{1} V_{1} /$ pre $-F_{1} V_{1} \times 100$. Bronchial reversibility is defined as a drug-induced increase in $\mathrm{FEV}_{1}$ of $\geq 200 \mathrm{~mL}$ and $\geq 12 \%$ above baseline.

\section{Statistical assessment}

Results are presented as mean \pm standard deviation. Statistical significance was at $P<0.05$. Descriptive group data were compared using the unpaired Student's $t$-test and the Pearson chi-square test.

\section{Ethical statement}

The study was performed in accordance with the ethical principles of the Good Clinical Practice guidelines and with applicable local regulatory requirements. The protocol was approved by local ethics review boards. All patients read the patient information form about the study procedure, and written informed consents were obtained.

\section{Results}

The baseline characteristics of patients are presented in Table 1. The female-to-male ratio was $4: 17$ and the mean age was $54.1 \pm 12.8$ years. The mean body mass index (BMI) was $26.0 \pm 4.4 \mathrm{~kg} / \mathrm{m}^{2}$. Eighty five point seven percent of patients were current smokers, $9.5 \%$ of patients were ex-smokers, and $4.8 \%$ of patients were nonsmokers. Pulmonary function test results and MIP values are presented in Table 2. The baseline spirometry results were: mean $\mathrm{FVC}, 3,017 \pm 1,020 \mathrm{~mL}$ and $75.8 \% \pm 20.8 \%$; mean $\mathrm{FEV}_{1}, 1,892 \pm 701 \mathrm{~mL}$ and $59.2 \% \pm 18.2 \%$; $\mathrm{FEV}_{1} / \mathrm{FVC}, 62.9 \% \pm 5.5 \%$; peak expiratory flow (PEF), $53 \% \pm 19 \%$. The pre-bronchodilator mean MIP value was $62.1 \pm 36.9 \mathrm{cmH}_{2} \mathrm{O}$. A positive reversibility test with salbutamol was found in $61.9 \%$ of patients. The absolute change and percentage change in $\mathrm{FEV}_{1}$ were $318 \pm 223 \mathrm{~mL}$ and 
Table I Characteristics of patients

\begin{tabular}{ll}
\hline Characteristic & $\mathbf{n}, \%$ \\
\hline Number of patients & 21 \\
Age (years) & \\
Mean \pm SD & $54.1 \pm 12.8$ \\
$\quad$ Range & $32-82$ \\
Sex (\%) & \\
Male & 81 \\
Female & 19 \\
BMl (kg/m ${ }^{2}$ ) & \\
Mean \pm SD & $26 \pm 4.4$ \\
Range & $19.8-35.2$ \\
Smoking (\%) & \\
Nonsmoker & 4.8 \\
Ex-smoker & 9.5 \\
Current smoker & 85.7 \\
Reversibility (\%) & \\
Yes & 61.9 \\
No & 38.1 \\
\hline A
\end{tabular}

Abbreviations: $\mathrm{SD}$, standard deviation; BMI, body mass index.

$19.8 \% \pm 16.7 \%$, respectively. The MIP value was increased by $5.5 \mathrm{cmH}_{2} \mathrm{O}(8.8 \%)$ and was $67.7 \pm 30.3 \mathrm{cmH}_{2} \mathrm{O}$ after bronchodilator. The relationship between the changes in MIP with age, $\mathrm{FEV}_{1}$, BMI, and reversibility are shown in Table 3. There was no significant relationship between age, $\mathrm{FEV}_{1}$, reversibility, and change in MIP with bronchodilator. However, the increase in MIP with bronchodilator was higher in patients with low BMI $\left(<25 \mathrm{~kg} / \mathrm{m}^{2}\right)(P<0.05)$.

\section{Discussion}

According to our knowledge, this is the first study to have investigated the relationship between change in MIP and bronchodilator. Therefore, this discussion is limited. MIP and

Table 2 Pre- and post-bronchodilator pulmonary function test results and MIP values

\begin{tabular}{lccc}
\hline & $\begin{array}{l}\text { Pre- } \\
\text { bronchodilator }\end{array}$ & $\begin{array}{l}\text { Post- } \\
\text { bronchodilator }\end{array}$ & Change \\
\hline FVC & & & \\
$\quad \begin{array}{l}\text { Mean } \pm \text { SD }(\mathrm{mL}) \\
\text { \% predicted } \pm \text { SD }\end{array}$ & $3,017 \pm 1,020$ & $3,232 \pm 963$ & $215 \pm 291$ \\
FEV & $75.8 \pm 20.8$ & $82.7 \pm 16.8$ & $13.1 \pm 22.5$ \\
$\quad$ Mean \pm SD $(\mathrm{mL})$ & $1,892 \pm 701$ & $2,210 \pm 791$ & $318 \pm 223$ \\
$\quad \%$ predicted \pm SD & $59.2 \pm 18.2$ & $69.6 \pm 18.6$ & $19.8 \pm 16.7$ \\
FEV $/$ FVC & & & \\
$\quad$ Mean \pm SD $(\%)$ & $62.9 \pm 5.5$ & $67.7 \pm 10.7$ & $8.7 \pm 8.9$ \\
PEF & & & \\
$\quad$ Mean \pm SD (\%) & $53 \pm 19.0$ & $62.1 \pm 19.2$ & $20.2 \pm 15.0$ \\
MIP $\left(\mathrm{cmH}_{2} \mathrm{O}\right)$ & $62.1 \pm 36.0$ & $67.7 \pm 30.3$ & $8.8 \pm 20.7$ \\
\hline
\end{tabular}

Abbreviations: MIP, maximal inspiratory pressure; FVC, forced vital capacity; $\mathrm{SD}$, standard deviation; $\mathrm{FEV}_{1}$, forced expiratory volume in I second; PEF, peak expiratory flow.
Table 3 The relationship between the changes in MIP with disease characteristics

\begin{tabular}{|c|c|c|c|}
\hline & \multicolumn{2}{|l|}{ MIP $\left(\mathrm{cmH}_{2} \mathrm{O}\right)$} & \multirow[t]{2}{*}{ Change } \\
\hline & $\begin{array}{l}\text { Pre- } \\
\text { bronchodilator }\end{array}$ & $\begin{array}{l}\text { Post- } \\
\text { bronchodilator }\end{array}$ & \\
\hline \multicolumn{4}{|l|}{ Age (years) } \\
\hline$<55(n=13)$ & $71.4 \pm 38.2$ & $75.0 \pm 31.3$ & $3.5 \pm 15.3$ \\
\hline$>55(\mathrm{n}=8)$ & $47.1 \pm 28.0$ & $56.0 \pm 26.4$ & $8.8 \pm 7.4$ \\
\hline \multicolumn{4}{|l|}{ FEV } \\
\hline$\geq 80 \%(n=2)$ & $55.0 \pm 4.2$ & $58.0 \pm 19.2$ & $3.0 \pm 15.5$ \\
\hline $80 \%-50 \%(n=13)$ & $71.9 \pm 40.8$ & $77.6 \pm 33.1$ & $5.7 \pm 14.7$ \\
\hline$<50 \%(\mathrm{n}=6)$ & $43.3 \pm 22.2$ & $49.6 \pm 16.6$ & $6.0 \pm 5.6$ \\
\hline \multicolumn{4}{|l|}{ BMI } \\
\hline$<25(\mathrm{n}=13)$ & $54.7 \pm 24.3 *$ & $62.2 \pm 25.1$ & $7.8 \pm 10.3$ \\
\hline$\geq 25(n=8)$ & $74.2 \pm 49.2$ & $76.1 \pm 37.7$ & $1.8 \pm 16.4$ \\
\hline \multicolumn{4}{|l|}{ Reversibility } \\
\hline Yes $(n=13)$ & $68.3 \pm 41.1$ & $73.9 \pm 33.2$ & $5.5 \pm 14.4$ \\
\hline No $(n=8)$ & $52.1 \pm 24.8$ & $57.7 \pm 23.6$ & $5.6 \pm 10.9$ \\
\hline
\end{tabular}

Note: $* P<0.05$.

Abbreviations: MIP, maximal inspiratory pressure; $\mathrm{FEV}_{1}$, forced expiratory volume in I second; BMI, body mass index.

MEP values were lower in patients with severe obstruction, compared with healthy subjects. MIP decreased also in patients with mild and moderate functional impairment. As with vital capacity, a high MIP (say, $>80 \mathrm{cmH}_{2} \mathrm{O}$ ) is of great value in excluding clinically-important inspiratory muscle weakness. ${ }^{6}$ The factors contributing to respiratory muscle weakness in patients with COPD are: a) malnutrition-related biochemical, anatomical, and physiological changes; b) muscular atrophy; c) steroid-induced myopathy; d) pulmonary hyperinflation with increased residual volume; e) reduced blood flow to the respiratory muscles..$^{7-13}$ Terzano et al reported a mean MIP value of $77 \pm 28 \mathrm{cmH}_{2} \mathrm{O}$ in COPD patients, with mean FVC, $\mathrm{FEV}_{1}$, and PEF results as $77 \% \pm 18 \%, 65 \% \pm 22 \%$, and $70 \% \pm 24 \%$, respectively. ${ }^{1}$ In our study, the mean MIP value $(62.1 \pm 36$ $\mathrm{cmH}_{2} \mathrm{O}$ ) was lower than Terzano's study, because the mean $\mathrm{FEV}_{1}$ was lower $(59.2 \% \pm 18.2 \%)$. Akkoca et al reported mean MIP values as $43.6 \pm 4.5 \mathrm{cmH}_{2} \mathrm{O}$ (in patients with $\mathrm{FEV}_{1} \leq 49 \%$ ) and $67.7 \pm 5.5 \mathrm{cmH}_{2} \mathrm{O}$ (in patients with $\mathrm{FEV}_{1} \geq 50 \%$ ). ${ }^{14}$ These values are consistent with our results.

In the present study, the reversibility test was found to be positive in $61.9 \%$ of patients. The absolute change and percentage of change in $\mathrm{FEV}_{1}$ were $317 \pm 223 \mathrm{~mL}$ and $19.8 \% \pm 16.7 \%$, respectively. The MIP value was increased by $8.8 \%$ after bronchodilator. To our knowledge, there are no other such results in the literature. There is a need for similar studies with larger numbers of patients; our study may provide guidance.

The change in MIP with bronchodilator was not affected by age, $\mathrm{FEV}_{1}$, or reversibilty. But it was affected by BMI, 
and the increase in MIP with bronchodilator was higher in patients with low BMI $\left(<25 \mathrm{~kg} / \mathrm{m}^{2}\right)$. Terzano et al showed a significant linear relationship between respiratory muscle pressure and height, as seen in our patients. ${ }^{1}$

In conclusion, when we perform the reversibility test with salbutamol in patients with airway obstruction, we noted a $13.1 \%$ increase in FVC, $19.8 \%$ increase in $\mathrm{FEV}_{1}, 20.2 \%$ increase in PEF, and 8.8\% increase in MIP. MIP increases with bronchodilator therapy, regardless of changes in lung function. The reversibilty test with salbutamol can be used to evaluate MIP changes.

\section{Disclosure}

The authors report no conflicts of interest in this work.

\section{References}

1. Terzano C, Ceccarelli D, Conti V, Graziani E, Ricci A, Petroianni A. Maximal respiratory static pressures in patients with different stages of COPD severity. Respir Res. 2008;9:8.

2. Black LF, Hyatt RE. Maximal respiratory pressure: normal values and relationship to age and sex. Am Rev Respis Dis. 1969;99(5):696-702.

3. Karvonen J, Saarelainen S, Nieminen MM. Measurement of respiratory muscle forces based on maximal inspiratory and expiratory pressures. Respiration. 1994;61(1):28-31.

4. Syabbalo N. Assessment of respiratory muscle function and strength. Postgrad Med J. 1998;74(870):208-215.
5. Ozkaya S, Dirican A, Tuna T. The effects of long-acting $\beta 2$-agonists plus inhaled corticosteroids for early reversibility in patients with airway obstruction. J Thorac Dis. 2013;5(4):461-465.

6. Hamnegard C-H, Wragg S, Kyroussis D, Aquilina R, Moxham J, Green M. Portable measurement of maximum mouth pressures. Eur Respir J. 1994;7(2):398-401.

7. Skeletal Muscle Dysfunction in Chronic Obstructive Pulmonary Disease. American Journal of Respiratory and Critical Care Medicine, Vol. 159, Skeletal Muscle Dysfunction in Chronic Obstructive Pulmonary Disease (1999), pp. S2-S40.

8. Rochester DF. Malnutrition and the respiratory muscles. Clin Chest Med. 1986;7(1):91-99.

9. Openbrier DR, Irwin MM, Rogers RM, et al. Nutritional status and lung function in patients with emphysema and chronic bronchitis. Chest. 1983;83(1):17-22.

10. Decramer M, Stas KJ. Corticosteroid-induced myopathy involving respiratory muscles in patients with chronic obstructive pulmonary disease or asthma. Am Rev Respir Dis. 1992;146(3):800-802.

11. Van Balkom RH, Zhan WZ, Prakash YS, Dekhuijzen PN, Sieck GC. Corticosteroid effects on isotonic contractile properties of rat diaphragm muscle. J Appl Physiol (1985). 1997;83(4):1062-1067.

12. Nishimura $Y$, Tsutsumi M, Nakata $H$, Tsunenari T, Maeda $H$, Yokoyama M. Relationship between respiratory muscle strength and lean body mass in men with COPD. Chest. 1995;107(5):1232-1236.

13. Heijdra YF, Dekhuijzen PN, van Herwaarden CL, Folgering HT. Effects of body position, hyperinflation, and blood gas tensions on maximal respiratory pressures in patients with chronic obstructive pulmonary disease. Thorax. 1994;49(5):453-458.

14. Akkoca O, Demir G, Saryal S, Karabiyikoğlu G. [The effect of hyperinflation on respiratory muscles and breathing pattern in COPD]. Tuberk Toraks. 2003;51(3):244-252. Turkish.
International Journal of COPD

\section{Publish your work in this journal}

The International Journal of COPD is an international, peer-reviewed journal of therapeutics and pharmacology focusing on concise rapid reporting of clinical studies and reviews in COPD. Special focus is given to the pathophysiological processes underlying the disease, intervention programs, patient focused education, and self management protocols.

\section{Dovepress}

This journal is indexed on PubMed Central, MedLine and CAS. The manuscript management system is completely online and includes a very quick and fair peer-review system, which is all easy to use. Visit $\mathrm{http}: / /$ www.dovepress.com/testimonials.php to read real quotes from published authors. 